\title{
Desgaste mental de assistentes sociais: um estudo na área da habitação*
}

\section{Social workers mental strain: a study in the dwelling area}

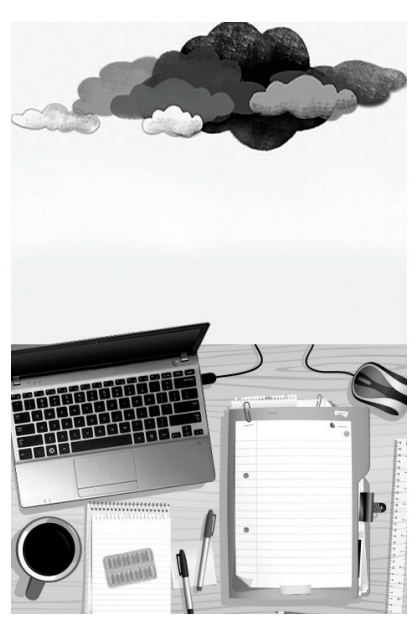

\author{
Damares Vicente** \\ Assistente Social, doutora em Serviço Social pelo Programa de Estudos \\ Pós-Graduados em Serviço Social da PUC-SP/São Paulo, Brasil.
}

Resumo: O presente artigo sintetiza reflexões sobre como as formas de organização e gestão do trabalho de assistentes sociais com as políticas sociais, na atual fase do capitalismo, são potencialmente geradoras de desgaste mental. A partir da análise de relatos, em pesquisa qualitativa na área de habitação de interesse social, ficaram evidenciados sofrimentos e adoecimentos que necessitam ser conhecidos e divulgados para contribuir com a organização coletiva de assistentes sociais.

Palavras-chave: Trabalho. Desgaste mental. Assistente social. Adoecimento. Sofrimento.

\begin{abstract}
In the present article it is synthesized thinking about how the ways social workers' work is organized and managed, together with social policies, are potential generators of mental strain. From the analysis of reports in qualitative research in the area of dwelling of social interest, it became evident suffering and illnesses that have to be known and unveiled to contribute to the social workers' collective organization.
\end{abstract}

Keywords: Work. Mental strain. Social worker. Illness. Suffering.

* Artigo com base em pesquisa de estágio pós-doutoral (2013-2014) realizado no Programa de Estudos Pós-Graduados em Serviço Social da PUC-SP, no Núcleo de Estudos e Pesquisas sobre Trabalho e Profissão, sob a supervisão da profa. dra. Raquel Raichelis Degenszajn. Meus profundos agradecimentos a ela, bem como às assistentes sociais que possibilitaram a realização da pesquisa.

**E-mail: datha@uol.com.br. 


\section{Introdução}

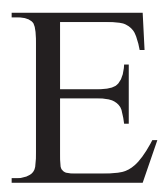

ste artigo apresenta reflexões a partir de pesquisa ${ }^{1}$ realizada pela autora sobre o desgaste mental de assistentes sociais relacionado ao trabalho, na área de Habitação de Interesse Social (HIS) da Secretaria Municipal da Habitação na cidade de São Paulo. A escolha do tema e da área se deu em razão da escassez de literatura sobre as especificidades contidas no processamento do trabalho de assistentes sociais nesse campo ${ }^{2}$ e objetivou realizar uma aproximação às condições de trabalho geradoras de sofrimento e adoecimento.

Partimos do entendimento que a crise capitalista deflagrada a partir dos anos 1970, instaurando a atual fase do capitalismo, monopolista e financeirizada, determinou uma transformação substantiva no mundo do trabalho, criando novas e articulando velhas formas de exploração, operando com intensa precarização do trabalho e com a banalização da vida, trazendo novos sofrimentos, adoecimentos e constrangimentos éticos e políticos aos(às) trabalhadores(as).

Podemos inferir que também o trabalho de assistentes sociais, como profissão inserida na divisão social, técnica (e sexual) do trabalho, sofre transformações em seu processamento, alterando significados e conteúdos, com consequências deletérias na vida e na saúde de profissionais, em virtude das exigências colocadas no cotidiano da profissão, conforme Raichelis (2011) e Raichelis e Vicente (2014).

O processamento do trabalho de assistentes sociais está se realizando cada vez mais em meio à violência e em condições precárias (de contratos, de salários e de meios) e as queixas de sofrimento têm sido cada vez mais frequentes.

No que se refere ao sofrimento e mesmo aos agravos gerados pelo trabalho à saúde mental, ainda observamos certo ceticismo, sendo comuns algumas questões, como, por exemplo: "Como saber se os agravos de que padecem as pessoas são mesmo relativos ao trabalho? Afinal, a vida é difícil, e até andar pelas ruas pode causar adoecimentos"; "É preciso separar os problemas pessoais, familiares, dos problemas do trabalho!"; "Outras pessoas também estão sujeitas a essas situações

1. A pesquisa qualitativa foi realizada por meio de entrevistas semiestruturadas (com roteiro flexível, gravação, transcrição, TCLE e sigilo). O "ponto de saturação" foi atingido com quatro entrevistas.

2. Sobre o trabalho de assistentes sociais em processos de remoção ver Vieira, 2015. 
e não adoecem. Não seriam o sofrimento e o adoecimento uma espécie de incapacidade pessoal de lidar com situações difíceis?”.

É fato que pessoas submetidas às mesmas situações adversas e pressões podem ou não adoecer, assim como podem apresentar níveis diferentes de sofrimento, e várias situações que geram sofrimento para alguns podem gerar prazer para outros (Brant; Minayo-Gomes, 2004). Entretanto, apenas a observação empírica da situação não nos permite afirmar que quem "suporta" as pressões seja uma pessoa "forte" e, ao contrário, quem adoece seja uma pessoa "fraca".

Não é fato, no entanto, que seja possível separar, de forma mecânica, um ser social em dimensões distintas e estanques. Analisando a "jornada de humilhações" de trabalhadores(as), Barreto (2003) afirma que "a relação emoção, trabalho e doença continua sendo vista na linearidade cartesiana das causalidades e somatizações" (p. 39).

Nessa aproximação, vimos reveladas depressões, angústias, ansiedades, inseguranças e temores. Nosso estudo possibilitou confirmar, de acordo com Raichelis (2011 e 2013) e Raichelis e Vicente (2014), que assistentes sociais também vêm sofrendo as consequências da precarização do trabalho, de forma dolorosa, intensa e solitária.

\section{0 desgaste mental $\mathrm{e}$ trabahho dominado ${ }^{3}$}

A formulação de desgaste mental de Seligmann-Silva (2011) permite conhecer como se processa e como se encrava na vida de trabalhadores(as) o sofrimento causado pelas relações de produção e reprodução capitalistas. Essa abordagem permite realizar estudos e pesquisas que privilegiem as experiências de trabalhadores(as), associadas às observações das condições objetivas de trabalho: das exposições físicas até as formas mais sutis de organização e gestão do trabalho visando a dominação do corpo e da subjetividade para a extração de mais-valia.

Laurell e Noriega (1989), precursores dos estudos sobre o desgaste operário, o definem como "os elementos que interatuam dinamicamente entre si e com o

3. "Dominação que em geral ultrapassa as fronteiras do trabalho propriamente dito e atinge os próprios seres, sem seu cotidiano, sua saúde e perspectiva existencial” (Seligmann-Silva, 2011, p. 181) 
corpo do trabalhador, gerando aqueles processos de adaptação que se traduzem em desgaste, entendido como perda da capacidade potencial e/ou efetiva corporal e psíquica" (p. 110). Os autores propuseram uma metodologia de pesquisa trabalhando com indicadores de cunho quantitativo e qualitativo e, fundamentalmente, com as falas dos operários, relatadas em grupos e individualmente. A proposta não previa apenas a pesquisa, mas, sobretudo, a reflexão coletiva sobre as condições de trabalho, visando a sua transformação.

No mesmo texto encontramos o relato da construção da investigação empreendida pelos autores com os trabalhadores de uma empresa mineradora, demonstrando como se constroem estudos que possibilitam a articulação entre o processo de produção e o desgaste operário. Nessa elaboração, as experiências italianas do Modelo Operário Italiano (MOI) foram analisadas e parcialmente incorporadas.

Segundo Seligmann-Silva (2011), a formulação de desgaste mental no trabalho baseia-se inicialmente no conceito de "desgaste operário" proposto por Laurell, por tratar-se de uma abordagem integradora construída com base no materialismo dialético.

O desafio metodológico dessa abordagem, segundo a autora, é o de construir uma forma de pensar interdisciplinar, combatendo reducionismos e construindo estudos e pesquisas que levem à formulação de políticas públicas. Considera que o conceito de desgaste mental e o modelo proposto para investigação são integradores, pois articulam outras duas importantes contribuições ou modelos: o do estresse e o da psicodinâmica do trabalho (PDT). Em linhas breves, o estresse, já classificado na Classificação Internacional de Doenças (CID-10), se acrescido de rubricas que identificam fatores sociais que interferem no estado de saúde, caracteriza, embora precariamente, o nexo causal, para fins previdenciários, entre o agravo e o adoecimento pelo trabalho. Essa abordagem, ainda segundo Seligmann-Silva, é considerada insuficiente para analisar "a complexidade das interações que se verificam entre os estressores vinculados à situação de trabalho", pois não ficam nítidas as mudanças subjetivas presentes nas origens dos diferentes transtornos mentais relacionados ao trabalho (2011, p. 129).

Já as perspectivas psicanalíticas, contextualizadas, como adverte a autora, permitem compreensões das dinâmicas intersubjetivas e intrapsíquicas de grande valor pela ampliação trazida por essa disciplina para o conhecimento dos sentimentos e dos ressentimentos, enquanto importantes aspectos das origens de adoecimentos. 
O destaque das contribuições psicanalíticas é dado por Seligmann-Silva aos conhecimentos produzidos no âmbito da psicodinâmica do trabalho. Conclui que o conceito de desgaste, tal qual formulado inicialmente por Laurell e Noriega, permite a inclusão de outro modelo, compreendido como:

Produto de uma correlação desigual de poderes impostos sobre o trabalho e sobre o trabalhador, acionando forças que incidem no processo biopsicossocial saúde-doença. Ou melhor, uma correlação de poderes e forças em que o executante do trabalho se torna perdedor. (Seligmann-Silva, 2011, p. 135)

E, para melhor definir o conceito de desgaste, aponta:

Nas interseções entre processo de trabalho e processo saúde-doença, determinações de ordem sociopolítica e econômica passam a atuar. Nas situações de trabalho dominado, a desvantagem que faz com que o corpo e os potenciais psíquicos do trabalhador sejam consumidos pelo processo de trabalho e por constrangimentos a ele vinculados se configura como desgaste. (Idem, p. 136)

Refere que há no trabalho alienado, incorporando as perspectivas teóricas da questão da alienação, uma "utilização deformada e deformante das potencialidades psíquicas, assim como do próprio corpo" (2011, p. 135; grifos da autora).

Nessa linha analítica torna-se inevitável tocar na questão dos afetos, mais especificamente no sofrimento. Para fins desta análise, consideramos sofrimento implicado no desgaste mental, aquele que se instala e se aprofunda sugando as capacidades psicofísicas do sujeito e determinando uma perda temporária ou definitiva de potencialidades e capacidades em virtude da exposição às injustiças, humilhações e desqualificações no percurso de uma vida laborativa, esvaindo-se a esperança de reversão das situações (Barreto, 2003; Laurell e Noriega, 1989; Dejours, 1991; Seligmann-Silva, 2011; Alves, 2013; Werlang e Mendes, 2013).

Werlang e Mendes (2013), a partir de estudos de Bordieu Castel; Dejours e outros examinam o sofrimento referindo-o à precariedade dos espaços de vida, incluindo o trabalho, definindo assim o sofrimento social: aquele que se encontra nas entranhas dos estados de precariedade, implicando a perda da vida e o medo da perda da saúde, do trabalho, dos vínculos, do sentido da vida, enfim (p. 743).

A análise empreendida pelas autoras estabelece intensidades e gravidades para o sofrimento, buscando estabelecer fronteiras que permitam observação e ação, 
"objetivando fazer retroceder os investimentos do capital sobre o humano, geradores da precariedade exacerbada" (Werlang e Mendes, 2013, p. 766).

Atento ao discurso de operários, Dejours (1991, p. 49), nas experiências que analisou típicas do taylorismo, identificou que a indignidade, o sentimento de inutilidade, a desqualificação e o esvaziamento do conteúdo significativo do trabalho são elementos potencialmente geradores de sofrimento e da vivência depressiva, que se efetivam quando a "certeza de que o nível atingido de insatisfação não pode mais diminuir" (p. 52).

Brant e Minayo-Gomez (2004) também realizam uma análise no sentido de trazer para o debate no campo da saúde do(a) trabalhador(a) a questão do sofrimento "sem adjetivos" (físico, psíquico, moral etc.), compreendendo que qualificá-lo poderia ser interpretado como uma segmentação. Consideram que a discussão de "qualidade de vida" encobre o sofrimento causado pelo trabalho e a relação sofrimento-adoecimento. Em artigo posterior, os autores referidos, apoiados em estudo de Brant e Dias (2004), citam como achado de pesquisa, uma incidência significativamente maior de relatos de sofrimento no gênero feminino (Brand e Minayo-Gomes, 2005, p. 941), ao qual pertence boa parte das trabalhadoras no setor de serviços (inclusive assistentes sociais) em situações precárias, com as remunerações mais baixas e jornadas extensivas de trabalho no âmbito privado, na indispensável, invisível e não remunerada reprodução social da classe trabalhadora.

Poderíamos considerar que homens e mulheres possuem modos diferentes de sentir, sofrer e verbalizar o sofrimento causado pelo trabalho? Se considerarmos que o trabalho implica sofrimento e prazer, conforme Dejours (1991); se o sofrimento é social, como afirmam Werlang e Mendes (2013); e se para impedir que o sofrimento nos despedace é necessário constituir sutis e sofisticadas formas de resistência, certamente as marcas de gênero estarão presentes.

Em nossa pesquisa surgiram questões relativas às desigualdades de gênero na vida doméstica, entretanto, quase nada sobre as relações desiguais de gênero no trabalho, apesar de ser a área da construção civil grande empregadora de trabalhadores do sexo masculino.

O prazer em realizar o trabalho também surgiu nas falas das assistentes sociais e estava referido a momentos de planejamento conjunto do trabalho, à articulação da equipe, ao desenvolvimento de ações na direção da garantia de direitos da população e, principalmente, quando a autonomia, ainda que relativa, era respeitada por chefias e colegas de equipe. 


\section{Tensões e contradições na gestão do trabalho de assistentes sociais com as expressões da questão social}

Tomamos como ponto de partida para análise da situação de trabalho ${ }^{4}$ de assistentes sociais a inserção do Serviço Social como profissão na divisão social e técnica do trabalho, na (re)produção das relações sociais no movimento global do capital, enquanto especialização do trabalho coletivo.

Tal concepção, segundo Iamamoto (2007), tornou-se de domínio público, mas seus fundamentos carecem de maiores aprofundamentos por meio de pesquisas empíricas de situações concretas, para compreendermos os limites e as possibilidades colocados no processamento desse trabalho específico que interferem na direção social e na autonomia relativa de assistentes sociais.

Como profissão especializada na divisão social, técnica (e sexual) do trabalho coletivo, o Serviço Social encontra-se inserido no "setor de serviços". O serviço é resultado que toma forma, ou não, de um objeto tangível; quando não toma a forma de objeto material, os próprios efeitos do trabalho transformam-se em mercadorias. Quando esse serviço deixa de ser prestado diretamente a um usuário, vendendo-o ao capitalista que, por sua vez, o vende ao mercado, "teremos o modo de produção capitalista no setor de serviços" (Braverman, 1980, p. 303-304).

O mesmo autor afirma que existe uma necessidade intrínseca de interpenetração das esferas da produção material e da produção imaterial para a obtenção de mais-valia, seja o trabalho materializado em mercadorias tangíveis, seja no trabalho não material.

No que diz respeito à organização e à gestão do trabalho (material ou imaterial), na ordem social capitalista contemporânea, definida por Gaulejac (2007, p. 37) como hipermoderna, estaria ocorrendo um processo profundo e extenso de dominação irracional da racionalidade instrumental; têm-se hoje empresas gerenciais que se municiam de estudos matemáticos, bem como experimentais, sobre os processamentos do trabalho, visando à aplicação de um modelo de gestão centrado nas mentes dos(as) trabalhadores(as).

4. "Conjunto complexo que inclui as condições físicas, químicas e biológicas do ambiente do trabalho; os aspectos técnicos; a organização prescrita e a caracterização dos canais formais de comunicação e das relações interpessoais" (Seligmann-Silva, 2011, p. 255). 
Dessa forma, uma característica desse modelo de gestão seria a confusão entre razão (busca de respostas por meio do conhecimento) e racionalização (encontro de uma linguagem comum, com uma preocupação de objetividade) que, quando utilizada como resposta meramente instrumental em situações complexas e adversas, tende a neutralizar tudo que é perturbador e incômodo, sob a aparência de um raciocínio lógico (Gaulejac, 2007, p. 73).

Partindo dessas referências e analisando as particularidades do trabalho social na habitação, Paz e Taboada (2010, p. 45) nos informam que seu surgimento se deu "no contexto da configuração urbana, na segunda metade do século XX, relacionado à desigualdade social e à segregação socioespacial", agravados pela ditadura militar, quando da implantação do projeto de modernização conservadora no Brasil.

As primeiras empresas de construção civil brasileiras iniciaram suas atividades com a especulação urbana, mas foi na ditadura militar que o desenvolvimento desse tipo de empresa se consolidou vinculado organicamente ao Estado brasileiro, por meio da construção de habitações populares, garantindo sua sustentabilidade, apoiada no fundo público.

É recente na história do Brasil, praticamente a partir da Constituição Federal de 1988, o debate da questão urbana, inclusive no que se refere à habitação, com o objetivo de construir políticas sociais públicas que contemplem condições de moradia digna e inserção no tecido urbano para o imenso contingente da população residente em moradias precárias.

Também o trabalho social na habitação que possuía, inicialmente, um caráter mais administrativo, se modificou, adquirindo novos contornos a partir das lutas sociais durante o processo de redemocratização do país (Paz e Taboada, 2010). Em São Paulo, na gestão de Luiza Erundina de Sousa (1989-92), o trabalho social era desempenhado junto aos movimentos de moradia, nas favelas, nos cortiços e na construção de mutirões.

Já na gestão de Paulo Maluf (1993-96), embora mantida a natureza interventiva e relacional do trabalho, seu conteúdo, significados e direção ético-política se transformaram. Promoveu-se nesse momento uma grande reestruturação, por meio de constrangimentos, pressões e demissões, como parte da nova racionalidade assumida pelo Estado brasileiro pós-reestruturação produtiva.

O objetivo foi o de introduzir as empreiteiras, fortalecendo o modelo de financiamento da indústria da construção civil pelo fundo público e terceirizando o trabalho social, que passou a ser contratado pelas gerenciadoras sociais. O Serviço 
Social foi a reboque nesse processo, sendo requisitado para construir um consenso com a população que possibilitasse a entrada de máquinas e de operários, redesenhando as sociabilidades no espaço urbano.

Portanto, o modelo atual de gestão do trabalho no âmbito da política habitacional permite a contratação de assistentes sociais por meio de concurso público ou por intermédio das gerenciadoras sociais, empresas terceirizadas pelo poder público que frequentemente repassam atividades a outras empresas, as "quarteirizadas", com piores condições de contratos, salários, jornada e direitos.

A racionalidade desse modelo de contratação impacta nas relações, nos sentidos, nos significados e nos conteúdos do trabalho de assistentes sociais, evidenciando a dimensão qualitativa da precarização (Druck, 2013), configurando-se "trabalhadores(as) de primeira e de segunda categorias".

Observamos que nas relações entre as assistentes sociais ${ }^{5}$ que entrevistamos, essa afirmação de Druck se manifesta através da concepção que o valor útil do trabalho realizado por assistentes sociais vinculados(as) diretamente ao poder público encontra-se garantido por um saber (que se transforma em poder), originando uma desvalorização de trabalhos tidos como instrumentais e simples (desempenhados por assistentes sociais das gerenciadoras sociais) e aqueles supostamente mais intelectuais e complexos (desempenhados por assistentes sociais concursadas).

Nas situações relatadas pelas assistentes sociais fica evidenciada que a forma de gestão do trabalho promove uma segmentação considerando-o como um "produto", uma mercadoria a ser garantida através de métricas, metas e padronização de ações. Para tanto, recorre-se a um modelo de gestão que não deixa de fora constrangimentos e violações de direitos que impactam no trabalho e na vida desses(as) trabalhadores(as).

Para fins desta análise, foram selecionados e organizados alguns conteúdos, que, entretanto, não esgotam a diversidade e a riqueza dos sentidos do trabalho atribuídos pelas entrevistadas.

5. As quatro assistentes sociais entrevistadas possuíam o seguinte perfil: idade: 31(2); 32(1) e 47(1) anos. Três casadas e uma solteira. Duas contratadas por gerenciadoras pela CLT e duas concursadas pela Prefeitura de São Paulo; uma estatutária e outra pela CLT. Possuíam mais de cinco anos de experiência na área. Realizaram estágio na área de habitação, exceto uma. As concursadas possuíam experiência em gestão. Possuíam graduação em universidades bem avaliadas. 
Constrangimentos ético-políticos: para realização do trabalho convive-se cotidianamente com as intervenções urbanas pautadas pelas necessidades da população e pelos interesses da indústria da construção civil (uma das mais poderosas do capitalismo atual). Assim, numa remoção da população de uma área considerada de risco, quando são definidos critérios monetários para pagamento de indenização, frequentemente entram em jogo interesses de diversas ordens, em especial de lideranças políticas locais. Como a negociação com moradores é realizada por assistentes sociais, a instabilidade e a mudança constante de critérios, com ameaças explícitas ou veladas de retaliações, a integridade dos(as) profissionais fica atingida, ocasionando isolamento, desconfiança, medo e perda dos significados do trabalho.

Sobre essas situações, Seligmann-Silva (2011, p. 467) refere que se verifica nos modos de precarização do trabalho uma degradação ética e moral das relações interpessoais e inter-hierárquicas (e, no caso do Serviço Social, podemos incluir as relações com a população), ocasionando um desgaste ético nas relações, atingindo valores como a reciprocidade, o respeito, a confiança e o reconhecimento de cada um.

Assédio moral: o assédio moral sofrido pelas assistentes sociais entrevistadas é uma das formas mais utilizadas para constranger e submeter o(a) trabalhador(a). Baseado na humilhação (Barreto, 2003), na desqualificação, em geral pública, na rudeza e nas agressões já tradicionais no mundo do trabalho, transformaram-se em estratégia gerencialista (Gaulejac, 2007).

O método da precarização do trabalho por meio do assédio moral é baseado na subalternização do(a) trabalhador(a), alvejando persistentemente sua autoestima e a autoconfiança, a ponto de implantar dúvidas sobre suas competências e capacidades, que chegam ao limite de comprometer a capacidade de análise objetiva da realidade, o que pudemos observar com nitidez nos depoimentos.

O objetivo principal do assédio moral no trabalho de assistentes sociais, em nosso entendimento, é justamente a quebra da "espinha dorsal" da profissão. O uso do assédio moral como uma estratégia de gestão, no atual momento de aprofundamento da exploração do trabalho pelo capital, visa impedir que o(a) trabalhador(a) se pronuncie, questione, denuncie, exija garantias de direitos e, no limite, objetiva que o(a) trabalhador(a) peça transferência ou demissão. Outro importante objetivo da prática do assédio moral é impedir a articulação e a solidariedade entre trabalhadores(as).

Instaurados o medo, a insegurança, o ressentimento e o desconforto constantes, pode ser desencadeado um tipo de desvitalização, uma exaustão da capacidade 
de prospecção, de desejo e de estabelecer relações. Viver passa a ser um peso, um fardo a ser arrastado diariamente. Todas as relações ficam prejudicadas, inclusive as familiares. $\mathrm{O}$ dano pode chegar a ser permanente e incapacitante (irritabilidade excessiva, isolamento social, intolerância a estímulos, apatia, anedonia, incapacidade para tarefas rotineiras, descuido com a própria higiene e aparência, insônia ou hipersônia, perda de apetite e libido).

Intensificação do trabalho: a situação mais frequente de extração de mais trabalho, no caso específico de assistentes sociais que trabalham em gerenciadoras sociais, embora também esteja presente a gestão por resultados, é a extensão da jornada de trabalho sem pagamento de horas extras ou mesmo sem a possibilidade de constituir um "banco de horas", que é um mecanismo comum utilizado para o não pagamento de horas extras, adicionais noturnos etc.

Nas entrevistas realizadas solicitamos às assistentes sociais que descrevessem um dia típico de trabalho, o que nos permitiu realizar uma conta simples, especialmente das assistentes sociais contratadas pelas gerenciadoras: uma hora para deslocarem-se de suas casas ao centro da cidade, onde se situa a Secretaria de Habitação; mais duas horas até chegarem ao local de trabalho; mais seis horas de jornada de trabalho; mais duas horas de volta à Secretaria e uma hora para chegarem às suas casas. Tudo isso soma cerca de doze horas de dispêndio de energia, sendo metade delas remunerada, com quinze minutos de pausa para descanso e alimentação (com interrupções).

Precariedade das condições, dos meios e dos instrumentos de trabalho: em campo, as assistentes sociais contratadas pelas gerenciadoras trabalham com as condições determinadas e mantidas pelas construtoras. Apesar de existir uma padronização, frequentemente é desobedecida. Quando exigem condições mínimas de trabalho, como rampas de acesso para a população, ventilação (atendem dentro de contêineres), banheiros (usam banheiros de bares ou de moradores) etc., são, muitas vezes, consideradas inconvenientes e queixosas pelos responsáveis pelas obras.

A Secretaria de Habitação, além das construtoras, fornece meios de trabalho, mas especialmente para arquitetos(as) que visitam as áreas para tarefas pontuais, diferentemente de assistentes sociais, que permanecem na área do começo ao fim das obras. 
As condições materiais objetivas que possuem para execução do trabalho nos canteiros de obras muitas vezes são precárias e aviltantes: há falta de água nos sanitários, falta de limpeza dos postos, presença de roedores, falta de ventilação etc.

No que se refere aos danos causados pela falta de condições materiais à saúde mental de trabalhadores(as), sabemos que a fadiga é um importante sintoma. Entretanto, as assistentes sociais se referiram à revolta como o sentimento que prevalece nessas situações. Nesse sentido, verificamos novamente que a "ofensa à dignidade" é uma marca constante desse trabalho.

Exposições ao sol, poeira e esgotos a céu aberto: todas as entrevistadas referiram que em diversos momentos estiveram junto à população fora do horário de trabalho e em condições adversas: nas ocorrências de incêndios, enchentes, desabamentos etc., por acreditarem que era fundamental, em situações-limite, estar junto à população com a qual trabalhavam. Entretanto, há situações de exposição mais rotineiras que trazem riscos de acidentes, por exemplo, a circulação em locais com esgotos a céu aberto, com resíduos orgânicos e ambientais, com presença de insetos e em condições climáticas adversas.

Com relação aos equipamentos de segurança, recebem botas e capacetes, porém nem sempre adequados ao tipo de risco e no tamanho correto. Esses equipamentos (que são mínimos) são fornecidos pelas construtoras. Entretanto, outros insumos, como, por exemplo, filtro solar, somente é distribuído para funcionários das construtoras.

Ameaça iminente à vida: num dos relatos de assistente social contratada por gerenciadora, ouvimos que, após uma chacina, a assistente social foi destacada para realizar um cadastramento, procedimento instrumental e subsidiário, em detrimento de um trabalho de articulação e discussão coletiva com a população sobre violência.

O trabalho de cadastramento foi realizado pela assistente social no local onde ocorreu a morte da pessoa, ainda com todos os vestígios presentes, inclusive o próprio corpo, o que causou problemas sérios para a profissional, tanto de ordem psíquica quanto nas relações de trabalho, pois passou a ser ridicularizada pelas colegas pelo seu visível abalo.

O transtorno do estresse pós-traumático (TEPT) e outros, como psicoses e depressões podem ocorrer nessas situações. Trata-se de traumas causados por uma 
iminente ameaça à vida. Nessas situações, "a violência pode ter atingido diretamente a pessoa ou ela pode ter sido apenas testemunha de um evento violento em que outros tenham sido as vítimas" (Seligmann-Silva, 2011, p. 517).

Tráfico de drogas ilícitas: a sociabilidade determinada pelo negócio do tráfico de drogas ilícitas faz parte da realidade cotidiana da população e de trabalhadores(as) nos territórios mais periféricos da cidade. Estabelecem-se regras e códigos morais que, quando descumpridos, podem resultar em severas sanções, inclusive execuções.

Com relação ao trabalho realizado nessas circunstâncias, a suposta "proteção" das assistentes sociais vem da população e dos próprios negociantes do tráfico nas áreas, já que trabalham sem qualquer suporte institucional que lhes garanta um mínimo de proteção. Seus relatos sobre as condições de trabalho atestam o desamparo, a insegurança, a violência e a banalização da vida a que se encontram expostos(as) cotidianamente.

Acidentes de trabalho, exposição a riscos à integridade: a exposição aos acidentes vão desde o contato com animais peçonhentos até a necessidade de sair correndo, literalmente, para evitar agressões. Segundo um dos relatos, observam-se quedas de carro anfíbio, infecções por insetos e parasitas, apedrejamentos por falta de pagamento de auxílio-aluguel e acidentes com animais.

A penosidade no trabalho com as expressões da questão social: temos na natureza e no processamento do trabalho de assistentes sociais, constrangimentos, determinações e tensões advindos da própria divisão social e técnica do trabalho, bem como das contradições de natureza ideológica e política determinadas pelo caráter contra-hegemônico do projeto profissional, que busca efetivar direitos da classe trabalhadora.

Sabemos que o trabalho com as expressões da questão social é penoso. Assistentes sociais, ao se depararem com indivíduos, famílias e populações em situações de intensa privação e de violação de direitos, ficam expostos(as) a riscos de ordem objetiva e subjetiva, bem como aos mecanismos da alienação.

Compreendemos, como Raichelis (2013, p. 617), ao analisar as relações entre Estado, políticas sociais e trabalho no Brasil, que o "fordismo periférico" foi uma marca da implantação do capitalismo nacional, sempre apoiado em trabalhos precários e constrangimento de direitos. 
Assistentes sociais que trabalham na HIS defrontam-se cotidianamente com a precariedade das condições de moradia, exigindo, muitas vezes, a retirada de famílias, o que implica a perda de seus espaços de trabalho e de sociabilidade, pois sendo a propriedade da terra objeto de disputas entre classes, frequentemente assistentes sociais são requisitadas para desenvolver trabalhos que exigem firme direção ética; caso contrário, essas ações correrão na contramão dos direitos da população.

Essas ações de remoção, comuns no trabalho de assistentes sociais da área, podem ser realizados com avaliação criteriosa, com a participação da população em todas as suas fases, prevendo o reassentamento ou o remanejamento, de modo a garantir à população condição equivalente.

Entretanto, pelos relatos, esse trabalho tem sido demandado pelas gerenciadoras de forma meramente genérica e instrumental, como um rol de procedimentos-padrão, a ponto de observar-se uma metamorfose, ou seja, aquele trabalho duro, tenso, complexo e delicado, mas sobretudo fundamental na garantia de direitos, transforma-se num trabalho alienado e alienante, subtraído, portanto, de seu caráter de trabalho útil.

É comum também, nos processos de remoção, a requisição da intervenção de assistentes sociais na negociação direta com a população acerca do valor da indenização pela desapropriação, sem nenhum critério técnico, totalmente à mercê de interesses diversos e muitas vezes antagônicos presentes nas áreas.

Igualmente, é demandada a "gestão" dos resultados das remoções realizadas desnecessariamente, por meio do pagamento do aluguel social, cujo montante é insuficiente para pagamento de todas as famílias, o que resulta, por vezes, no privilégio de comunidades com maior articulação política em detrimento daquelas que se encontram isoladas e desarticuladas.

Essas situações promovem intensa desqualificação do trabalho e do(a) trabalhador(a), da vida de indivíduos e de famílias, podendo implicar uma sobrecarga psíquica (Laurell e Noriega, 1989), definida como "perda do controle sobre o trabalho [...]; a desqualificação do trabalho, resultado da separação entre concepção e execução; a parcelização do trabalho, que redunda em monotonia e repetitividade", implicando uma "hipotrofia do pensamento e da criatividade" (p. 112).

Além da frustração e da sensação de incompetência, pode ocorrer uma alteração da própria natureza do trabalho, se executado de modo fragmentado, esvaindo-se sentidos, significados e o reconhecimento da profissão perante as equipes e a população. 


\section{As manifestações de desgaste mental de assistentes sociais}

Nosso objetivo é o de compreender como as determinações atuais da gestão, da organização e das condições objetivas de trabalho incidem sobre a vida e a saúde, especialmente a saúde mental de assistentes sociais, na esfera da reprodução social da vida da classe trabalhadora. A seguir relacionamos alguns eventos significativos sobre suas angústias e agravos.

Distúrbios de sono: os distúrbios de sono (pesadelos e insônia) surgiram nos períodos em que estiveram sob assédio moral ou na iminência de sofrer ou de presenciar violações de direitos nas áreas em que trabalhavam.

Medo e crises de choro: todas as assistentes sociais relataram ter medo dos riscos à integridade física e das represálias da gestão (troca de postos de trabalho, humilhações, desqualificações, assédio, demissão).

Sentimento de impotência: as situações que presenciaram de violações de direitos da população, bem como o assédio moral de que foram vítimas incidiram fortemente em sua autoestima, pois desqualificavam suas competências éticas e suas potencialidades, operadas via autoritarismo nas relações de trabalho.

Depressões: o termo "depressão" é amplamente utilizado no cotidiano e traduz a tristeza profunda que retira a energia para prosseguir com a vida. A tristeza faz parte da experiência humana, entretanto, as situações às quais estamos nos referindo foram as que feriram suas humanidades, minando suas potências vitais.

Angústia/ansiedade: assistentes sociais vivem numa atmosfera de iniquidades e necessitam falar sobre isso; familiares e amigos são os principais interlocutores, porém há um limite para essa dinâmica. Quando praticamente a totalidade das relações fica tomada por essas temáticas, pode significar que os sentimentos originados nas experiências do trabalho dominado já não podem mais ser dimensionados subjetivamente; transbordam e tomam o lugar de outras experiências e sentimentos, avançando para a vida familiar.

Fadiga: o trabalho realizado utilizando como meios e instrumentos as capacidades intelectuais, relacionais e comunicacionais gera uma fadiga que se expressa pelo 
esgotamento físico, com a sensação permanente de cansaço, e implica perdas justamente nas capacidades intelectuais necessárias à realização do trabalho. Assim, computam-se outras perdas, como o "apagamento" de conhecimentos já adquiridos, os bloqueios de memória, a dificuldade de fixação de conceitos e a dificuldade de leitura de textos que exigem concentração e disciplina intelectual.

Alterações metabólicas: as situações de trabalho determinam, muitas vezes, o desrespeito às necessidades fisiológicas, conforme relatado. Mas, além disso, podem precipitar uma forma de lidar com as insatisfações, frustrações e constrangimentos, que se traduzem em prazeres compensatórios que apaziguam, ao menos de imediato, a turbulência mental. Podem ser alimentos; pode ser o consumo excessivo de bebidas alcoólicas e drogas lícitas, especialmente ansiolíticos, comuns entre trabalhadores(as) que permanecem muitas horas expostos a altos níveis de pressão e a atividades que oferecem riscos à integridade física e mental deles.

\section{As resistências}

Com relação às resistências, as assistentes sociais enfrentaram situações de assédio e de constrangimento no embate direto com as chefias, solicitando, no limite de suas resistências, a saída de postos de trabalho, atividades ou projetos.

No que se refere à equipe, as assistentes sociais concursadas pela Prefeitura encontraram nos colegas de trabalho apoio constante, o que não ocorreu com aquelas das gerenciadoras, que, ao contrário, foram isoladas e criticadas.

As entrevistadas apontaram como fundamental o apoio familiar; de amigos(as) e da religião, mais do que de medicamentos e acompanhamentos psiquiátricos e/ ou psicológicos. O recurso aos tratamentos psicoterápicos também foram citados, mas somente foram buscados a partir de manifestações mais severas. Com relação ao uso de álcool, obtivemos apenas uma fala trivial apontando como maneira de relaxar, "repartir", dividir a frustração. Algumas formas de resistências implicaram o abandono de postura mais cordata, com chefias e colegas de trabalho, por outra mais reativa aos ataques.

Como pudemos observar, as resistências foram exercidas individual e solitariamente, sem qualquer articulação com coletivos de trabalhadores(as) ou com os movimentos sociais de moradia, e mesmo com a população atendida. 


\section{Considerações finais}

Ao término desta análise avaliamos que para maior aprofundamento são necessários estudos de maior envergadura, de caráter interdisciplinar. Nesta inaugural aproximação buscamos relatar e examinar a situação de trabalho das assistentes sociais e as consequências deletérias sobre a vida delas.

A partir do referencial teórico-metodológico adotado, podemos considerar que na organização, gestão e processamento do trabalho das entrevistadas estão presentes condições, relações, demandas, instrumentos e técnicas que levaram ao desgaste mental, tal qual referido por Seligmann-Silva (2011) e Laurell (1989), enquanto perda de capacidade física/mental, potencial ou efetiva.

Observamos que a origem do sofrimento e do adoecimento localiza-se principalmente nas condições objetivas (organização, instrumentos e meios) promovidas pelas instituições públicas e privadas que demandam o trabalho profissional, utilizando novas e antigas formas de precarização e intensificação do trabalho assalariado, no atual contexto das transformações do mundo do trabalho e das políticas sociais.

Esse contexto nos demonstra a dinâmica das relações sociais de classes em disputa, asseverando a distância entre os objetivos institucionais e as necessidades e demandas da população, terreno no qual se move a profissão.

A atual gestão do trabalho nessa fase do capitalismo - financeirizado e monopolista - que promoveu intensa reestruturação no mundo do trabalho, no Estado e nas políticas sociais, precarizou ainda mais as condições objetivas e subjetivas no processamento do trabalho. Com raízes históricas profundas em práticas de assédio moral, corrupção, perseguições, entre outras, o sofrimento e o adoecimento nos pareceram consequências facilmente observáveis.

É importante asseverar o distanciamento político entre assistentes sociais e população organizada e "a organizar" justamente num contexto tensionado por profundas contradições. Dessa forma, fica distante a possibilidade de estabelecer estratégias político-institucionais "no sentido de reforçar as lutas das classes subalternas" (Iamamoto, 2007, p. 250).

Igualmente ao distanciamento político-organizativo observado, notamos uma frágil compreensão sobre o lugar destinado pelo capitalismo às mulheres na divisão sexual do trabalho, o que necessita ser explorado com mais afinco no debate 
profissional, para compreender "as nuanças da opressão e exploração das mulheres no âmbito da classe trabalhadora" (Iamamoto apud Cisne, 2012, p.14).

Finalizando, entendemos que dados os imensos desafios colocados no trabalho cotidiano, potencialmente gerador de sofrimentos, adoecimentos e desgaste mental, torna-se imprescindível realizar "pesquisas concretas sobre situações concretas", que desvendem o processamento do trabalho do assistente social" e

as formas por ele assumidas nos diferentes espaços ocupacionais, bem como as diversas atividades que desenvolvem no cotidiano das instituições [...], na relação com os diferentes empregadores institucionais, exigindo um diálogo cada vez mais próximo entre formação, exercício profissional, pesquisa e produção de conhecimento, refletindo acerca não só de sua dimensão útil, mas sobretudo sobre sua dimensão abstrata, condição inseparável de qualquer trabalho assalariado na ordem capitalista. (Raichelis, 2011, p. 435)

Acreditamos, e já temos elementos em estudo, ${ }^{6}$ que várias situações aqui descritas estão presentes também em outros espaços sócio-ocupacionais, caracterizando a violência no trabalho. Consideramos fundamental conhecê-las e divulga-las, para que possamos fortalecer as lutas da classe trabalhadora pelo direito ao trabalho e à vida.

Recebido em 27/5/2015 - Aprovado em 9/6/2015

\section{Referências bibliográficas}

ALBUQUERQUE, Valéria de Oliveira. Serviço Social e trabalho docente: precarização e intensificação do trabalho nas Instituições Privadas de Ensino Superior em São Paulo. Tese (Doutorado) - Programa de Estudos Pós-graduados em Serviço Social. Pontifícia Universidade Católica de São Paulo, São Paulo, 2015.

ALVES, Giovanni. Dimensões da precarização: ensaios de sociologia do trabalho. Bauru: Canal 6, 2013.

6. Araújo (2004); Ferreira (2010); Silva (2014); Delia e Seligmann-Silva (2014); Albuquerque (2015). 
ARAÚJO, Adriana Bispo. Estresse e trabalho: os assistentes sociais na mira do Burnout. Dissertação (Mestrado) - Programa de Estudos Pós-graduados em Serviço Social Pontifícia Universidade Católica de São Paulo, São Paulo, 2004.

BARRETO, Margarida. Violência, saúde e trabalho: uma jornada de humilhações. São Paulo: Educ/Fapesp, 2003.

BRANT; Luiz Carlos; MINAYO-GOMES, Carlos. A transformação do sofrimento em adoecimento: do nascimento da clínica à psicodinâmica do trabalho. Ciência \& Saúde Coletiva, Rio de Janeiro, n. 9, p. 213-223, 2004.

. O sofrimento e seus destinos na gestão do trabalho. Ciência \& Saúde Coletiva, Rio de Janeiro, n. 4, p. 939-952, 2005.

BRAVERMAN, Harry. Trabalho e capital monopolista: a degradação do trabalho no século XX. Rio de Janeiro: Zahar, 1980.

CISNE, Mirla. Gênero, divisão sexual do trabalho e Serviço Social. São Paulo: Editora Outras Expressões, 2012.

DELIA, Agda; SELIGMANN-SILVA, Edith. Trabalho e saúde no Tribunal de Justiça de São Paulo: repercussões na vida de seus trabalhadores. Relatório final de pesquisa. São Paulo: AASPTJ-SP/Affocos/Assojubs/Assojuris, 2014.

DEJOURS, Christophe. A loucura do trabalho: estudo de psicopatologia do trabalho. São Paulo: Cortez/Oboré, 1991.

DRUCK, Graça. A precarização social do trabalho no Brasil. In: ANTUNES, R. (Org.). Riqueza e miséria do trabalho no Brasil II. São Paulo: Boitempo, 2013.

FERREIRA, Joyce Pires. O processo de trabalho do assistente social judiciário no Tribunal de Justiça do estado de São Paulo: prazer, sofrimento e dor no cotidiano profissional. Monografia (Especialização em Serviço Social) — Universidade de Brasília (UnB)/Conselho Federal de Serviço Social (CFESS)/Associação Brasileira de Ensino e Pesquisa em Serviço Social (Abepss), Brasília, 2010.

GAULEJAC, Vincent. Gestão como doença social: ideologia, poder gerencialista e fragmentação social. Aparecida: Ideias \& Letras, 2007.

IAMAMOTO, Marilda Villela. Serviço Social em tempo de capital fetiche: capital financeiro, trabalho e questão social. São Paulo: Cortez, 2007.

LAURELL, Asa Cristina; NORIEGA, Mariano. Processo de produção e saúde: trabalho e desgaste operário. São Paulo: Hucitec, 1989.

MARTINELLI, Maria Lucia (Org.). Pesquisa qualitativa: um instigante desafio. São Paulo: Veras/Nepi, 1999. 
PAZ, Rosangela Dias Oliveira da; TABOADA, Kleyd Junqueira. Trajetória do trabalho social em habitação. Trabalho Social em Programas e Projetos de Habitação de Interesse Social. Curso a Distância, aulas 3 e 5, Módulo II. Brasília: Ministério das Cidades, 2010. Disponível em: <http:/www.capacidades.gov.br/biblioteca/detalhar/id/89/titulo/Trabalho+ social + em + programas + e + projetos + de + habitacao + de + interesse + social $/$ pagina/2 $>$. Acesso em: 5 abr. 2014.

RAICHELIS, Raquel. O assistente social como trabalhador assalariado: desafios frente às violações de seus direitos. Serviço Social \& Sociedade, São Paulo, n. 107, jul./set. 2011.

. Proteção social e trabalho do assistente social: tendências e disputas na conjuntura de crise mundial. Serviço Social \& Sociedade, São Paulo, n. 116, Especial: Proteção Social, out./dez. 2013.

; VICENTE, Damares. Metamorfoses do trabalho e da política social em tempo de crise mundial - implicações para o trabalho do assistente social. In: SEMINÁRIO DO TRABALHO: TRABALHO, EDUCAÇÃO E NEODESENVOLVIMENTISMO, 9., 2014, Marília, Unesp, 2014. Disponível em: <http://www.ronaldofrutuozo.com.br/seminariotrabalho2014/>. Acesso em: 26 mar. 2014.

SANTOS, João Bosco Feitosa; OSTERNE, Maria do Socorro Ferreira; ALMEIDA, Rosemary de Oliveira. A entrevista como técnica de pesquisa do mundo do trabalho. In: ALVES, Giovanni; SANTOS, João Bosco Feitosa (Orgs.). Métodos e técnicas de pesquisa sobre o mundo do trabalho. Bauru: Canal 6, 2014.

SELIGMANN-SILVA. Edith. Trabalho e desgaste mental: o direito de ser dono de si mesmo. São Paulo: Cortez, 2011.

SILVA, Ociana Donato. Assedio moral nas relações de trabalho do/a assistente social: uma questão emergente. Dissertação (Mestrado) — Programa de Estudos Pós-graduados em Serviço Social da Pontifícia Universidade Católica de São Paulo, São Paulo, 2014.

VIEIRA, Nuria Pardillos. O trabalho do assistente social nos processos de remoção de moradias: atualização de antigas requisições. Tese (Doutorado) — Programa de Estudos Pós-graduados em Serviço Social da Pontifícia Universidade Católica de São Paulo, São Paulo, 2015.

WERLANG, Rosangela; MENDES, Jussara Maria Rosa. Sofrimento social. Serviço Social \& Sociedade, São Paulo, n. 116, out./dez. 2013. 